\title{
Insects as food and feed: European perspectives on recent research and future priorities
}

\author{
C.L.R. Payne ${ }^{1,2 *}$, D. Dobermann ${ }^{3}$, A. Forkes ${ }^{4}$, J. House ${ }^{5}$, J. Josephs ${ }^{6}$, A. McBride ${ }^{7}$, A. Müller ${ }^{8}$, R.S. Quilliam ${ }^{9}$ and $^{-}$ \\ S. Soares ${ }^{4}$
}

${ }^{1}$ Conservation Science Group, Department of Zoology, David Attenborough Building, University of Cambridge, New Museums site, Cambridge, CB2 3QY, United Kingdom; ${ }^{2}$ British Heart Foundation Centre on Population Approaches for Non-Communicable Disease Prevention, Department of Population Health, New Richards Building, University of Oxford, Old Road Campus, Headington, OX3 7LF, United Kingdom; ${ }^{3}$ Rothamsted Research, Biological Chemistry and Crop Protection, West Common, Harpenden, AL5 2JQ, United Kingdom; ${ }^{4}$ Division of Mechanical Engineering and Design, School of Engineering, London South Bank University, 103 Borough Road, SE1 0AA London, United Kingdom; ${ }^{5}$ Department of Geography, University of Sheffield, Winter Street, Sheffield, S10 2TN, United Kingdom; ${ }^{6}$ The Bug Shack Ltd, 50 Harland Rd, Bournemouth, BH6 4DW, United Kingdom; ${ }^{7}$ School of Psychology, University of Southampton, Southampton, SO17 1BJ, United Kingdom; ${ }^{8}$ Department of Social Sciences, Humboldt-Universität zu Berlin, Universitätsstraße 3B, 10117 Berlin, Germany; ${ }^{9}$ Biological and Environmental Sciences, School of Natural Sciences, University of Stirling, Stirling, FK9 4LA, United Kingdom; charlotte.payne@gmail.com

Received: 23 February 2016 / Accepted: 30 May 2016

(C) 2016 Wageningen Academic Publishers

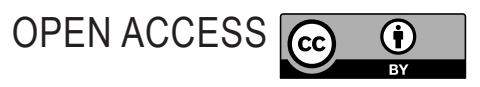

OPINION ARTICLE

\begin{abstract}
This paper discusses the current state and priorities of Europe-based research on insects as food and feed, based on presentations at a workshop held in December 2015, and discussions that followed. We divide research into studies that focus on farming, health and nutrition, and those that prioritise psychological, social and political concerns. Edible insects are not necessarily universally beneficial. However, certain food insects can convert organic waste material, and provide nutrient-rich protein for humans and animals. Recent research is not concordant when trying to identify social and psychological barriers to insects as food in Europe, indicating the complexity of the issue of consumer acceptance. Innovative means of marketing insects as food include 3D printing, scientific comics, and the promotion of rural food culture in an urban setting. Edible insects are intimately connected to strong cultural and regional values, and their increasing commercialisation may empower and/or disenfranchise those who hold such values. We conclude with a discussion about the future priorities of edible insect research in Europe. We acknowledge the political nature of the 'entomophagy' movement. With legislative change, the insect food industry potential presents an opportunity to challenge the dynamics of current food systems. We identify the following priorities for future research: the need to better understand environmental impacts of insect procurement on both a regional and global scale, to investigate factors affecting the safety and quality of insect foods, to acknowledge the complexity of consumer acceptance, and to monitor the social and economic impacts of this growing industry.
\end{abstract}

Keywords: entomophagy, food security, food systems, insect farming, insect industry

\section{Introduction}

The first interdisciplinary international meeting on insects as food and feed, the Insects to Feed the World conference (Vantomme et al., 2014), took place in May 2014 and was a three-day event that attracted 450 participants from 45 countries.
Since the 2014 conference, researchers and entrepreneurs have made rapid progress in the field of insects as food and feed. At least 61 companies producing and/or selling insects as food and feed were launched between 2014 and 2015 (Dossey et al., 2016), and during the same time period at least 93 original scientific research articles have been published on insects as human food (following the search 
protocol detailed in Müller et al. (2016) for the specified time period).

To keep pace with these developments, we felt it timely to hold a follow-up event, showcasing some of the current research in this field. The event focused largely but not exclusively on research based in European institutions, and comprised over 55 participants from at least seven different countries. The current paper summarises the novel research presented at the workshop, and situates it in a wider research context. We describe the main content, thereby assessing current developments and subsequently determining what they reveal about future research priorities.

\section{Farming, health and nutrition}

\section{Recent developments in insect farming for food and feed}

Insect farming is a growing industry with broad potential. Richard Quilliam from the University of Stirling in Scotland works on two projects that focus on exploiting insect larvae for the transformation of waste organic matter. Insects possess great potential to efficiently convert organic matter into a high value source of protein and fat (Van Huis, 2013), producing and refining insect larvae grown on organic waste into a high quality product has the potential to provide sustainable solutions for both waste management and food security (Čičková et al., 2015; Van Zanten et al., 2015). The first of the University of Stirling projects is ENTO-PRISE (http://www.stir.ac.uk/ento-prise/), which aims to commercialise black soldier fly (BSF) transformation of green wastes to benefit small-scale farmers in Ghana. Results have shown that BSF larvae can make a significant nutritional contribution to aquaculture and poultry systems, and the remaining insect frass makes a valuable organic biofertiliser that can enhance soil fertility and increase crop yields. The second project is AQUAFLY, which is led by the National Institute of Nutrition and Seafood Research (NIFES) in Norway. AQUAFLY aims to utilise the kelp fly (Coelopa spp.) fed on marine substrates such as seaweed biomass, in order to tailor an insect product rich in marine omega- 3 fatty acids, to supplement existing fishmeal options for sustainable Atlantic salmon aquaculture (https://www. nifes.no/en/prosjekt/insects-salmon-feed/). Both of these projects demonstrated the significant potential for insects to recover resources from organic wastes, and provide added value products such as high protein livestock feed and frass biofertilisers.

However, the use of insects as feed is a relatively new practice on a commercial scale, and many questions remain to be tackled. For instance, there are concerns about the risk of pathogen transfer in the production system. This is also being addressed at the University of Stirling, who will monitor pathogen transfer through an aquaculture feed chain as part of the AQUAFLY project (Swinscoe, 2015). A further concern is the socio-economic impact of involving rural communities in insect farming. Cultural acceptability, price stability and the sustainability of farming practices are key areas that require investigation alongside projects such as ENTOPRISE. As the field develops, more studies will be needed to monitor socio-economic change, ideally using participatory methods that engage the farmers themselves in the research process (Schnorr, 2015).

\section{Health and nutrition}

Understanding the implications of eating insects for human health and nutrition is key to assessing the potential of insects as food and feed. The question of whether edible insects can offer a 'healthy' alternative to conventional meat products can on the one hand be approached by looking at nutritional composition. However, such an approach may be limited by the quality of available data. A systematic review conducted by a research team at the University of Oxford looked at the nutrient composition of 10 commercially available edible insects and evaluated the evidence according to EuroFIR guidelines (Salvini et al., 2014). They found that data on the nutritional composition of edible insects tended to be of low quality compared to international standards (Payne et al., 2016). This makes it difficult to accurately test claims of the 'healthiness' of insects as food. A comparison of insect nutritional composition with that of conventional meats found greater disparity within 'insects' as a category. This study also evaluated the data according to two nutrient profiling models, one for combating over-nutrition and one for combating undernutrition. Although there were no significant differences between insect and livestock 'meats' in terms of their potential to combat over-nutrition, three insect species (crickets, honeybees and palm weevil larvae) were found to be nutritionally preferable to meats for combating under-nutrition. This lends support to efforts to promote invertebrates in developing countries where under-nutrition contributes to significantly higher mortality rates (e.g. Kuong et al., 2013). However, such studies are further limited by an absence of information on the bioavailability of key nutrients found in insects, the impact of different processing methods on nutrient composition, and also a lack of evidence that insects are acceptable meat substitutes in the quantities necessary for them to be nutritionally beneficial.

Yet given the global burden of undernutrition, such research should be prioritised. Worldwide, 178 million children are stunted, 19 million suffer from wasting and approximately $20 \%$ of women globally have a significantly low body mass (Black et al., 2008; Imdad and Bhutta, 2012). Yet the countries with the most malnutrition are also those countries with the richest availability of edible insects, which presents a unique opportunity for insects to improve nutritional status. One approach to this problem 
uses edible insects high in concentrations of micronutrients in malnutrition interventions in the developing world. This has previously been trialled by the WINFOODS project, which used wild edible termites to fortify complementary foods with key micronutrients, but did not find health improvements in subjects for any of the tested biomarkers (Konyole, 2014). Given their high nutrient content (Kinyuru et al., 2015), reasons for this lack of efficacy are unclear but may be linked to barriers to bioavailability and/or confounding factors. To address some of these issues, a new initiative by Darja Dobermann at Rothamsted Research (Harpenden, UK) combines investigations linking nutrition and health with the development of a sustainable breeding system for the insects in question. Dobermann examines the feasibility of breeding the commonly consumed African field cricket, Gryllus bimaculatus, on under-utilised biowastes found within Africa. The crickets will be bred on bio-waste sources such as beer brewing waste, cow manure and vegetable scraps. They will then be fed to humans or processed into meal for the aquaculture industry, which accounts for $15 \%$ of the protein intake of 3 billion people globally (Godfray et al., 2010). Results indicate that crickets can be successfully fed on various bio-wastes including the waste generated by the process of brewing millet beer, a very popular beverage in West Africa. Furthermore, variations in the drying temperature used in processing the crickets has a significant impact on lipid profiles, notably changing omega- 6 content. Investigations are ongoing into iron bioavailability and the consequences of different storage and processing techniques on nutrient composition of these crickets.

Overall, there is clear potential for insects as a food to combat malnutrition, although detailed and context-specific studies of nutrient content and nutrient bioavailability are recommended before this potential can be fully understood and applied. Furthermore, no insect is universally beneficial independent of its production context and its dietary role; these aspects must also be taken into account by research into the health and nutrition potential of insects as food and feed.

\section{The psychological, the social and the political}

\section{Marketing and psychology}

Consumer acceptance is frequently identified as a significant barrier to the adoption of insects as a food source in populations without a recent history of insect consumption. Existing research has looked at overall levels of acceptance in general population samples (Ruby et al., 2015; Verbeke, 2015) and examined willingness to consume in relation to attitudes, traits and demographic variables (e.g. Hartmann et al., 2015; Lensvelt and Steenbekkers, 2014; Schösler et al., 2012; Vanonhacker et al., 2013). A study undertaken at the University of Parma with 135 university students found that individual attitudes, based on the perceived environmental and health benefits of insects, were the most significant determinants of participants' willingness to consume products containing insect flour (Sogari et al., 2015). Yet, product attributes and contextual factors are also likely to exert a substantial influence on consumer acceptance, as some studies have suggested (e.g. Tan et al., 2016). The acceptance of a product containing insects is likely to depend on a combination of consumer traits, cultural exposure to insects as food, social and practical factors in the context of food provisioning and consumption, and the characteristics of specific products.

Thus far, systematic research on attitudes towards insects as food has predominantly focused on non-insect-eating populations, with mixed results. Regarding consumer traits, Jenny Josephs reported that in a preliminary survey of 53 students at the University of Southampton (Southampton, UK) $51 \%$ 'would not try' insects, primarily due to the perception that insect food 'is disgusting' or 'it would taste bad'. Hannah Tranter found that of 286 UK school children aged 12-15 (school years 8-10), 74\% responded 'yes' to the question 'should we consider eating insects?' (Tranter, 2013). In non-insect-eating populations, the presence and nature of cultural exposure to insects as food is a recent phenomenon, yet this may be a major factor in influencing acceptance. Notably, the media in non-insecteating countries tends to portray insect foods variously as novel, disgusting, healthy and/or ethically preferable to meat. Evidence suggests that this type of information may have a significant effect on consumer attitudes: a research group at the Universita degli Studi Napoli Frederico II in Naples, Italy, surveyed consumers in two European countries, Denmark and Italy ( $\mathrm{n}=282$ university students) and found that the impact of communication overrode other factors such as age, gender and nationality in influencing consumer attitudes. Within the study, communication about societal benefits had greater influence than those about benefits for the individual (Verneau et al., 2015). Thus communicating societal benefits may be a useful marketing strategy - yet given the lack of robust knowledge of the impacts of increased insect consumption, perhaps an irresponsible one. Finally, product characteristics are also a crucial factor in shaping acceptance. A further study from the Universita degli Studi Napoli Frederico II found that three characteristics increased consumer willingness to buy insect food products: reduction of the insects to flour, the addition of cacao flavouring and organic certification (Cavallo and Materia, 2015).

Few studies have considered the psychological dimensions of consumer acceptance in countries with a history of insect consumption (a notable recent exception being Tan et al., 2015), yet - particularly given evidence that the use of insects as food is in decline due to cultural and/ or environmental change (e.g. Yen, 2015) - such research 
is also crucial. In order to determine the key factors influencing insect consumption in Thailand, and potentially lead to programs that aim to encourage insect eating and sustainable farming practices, Josephs and McBride will use the COM-B (capability, opportunity, motivation and behaviour) model of behavioural change (Michie et al., 2014) to investigate three components (Capability, Opportunity and Motivation) that influence insect eating and farming, through interviews. Although previous studies have noted the direction and prevalence of dietary change with regard to insect consumption (e.g. DeFoliart, 1999; Payne, 2014), this will be the first study to explicitly focus on this phenomenon.

Yet in both contexts, researchers would benefit from an understanding of consumer acceptance that goes beyond individual attitudes and psychological traits, and also accounts for social, cultural and geographic factors affecting food choice, which are likely to be equally important. This is evident in the research of Jonas House at the University of Sheffield (Sheffield, UK), whose work on consumer acceptance of insect-based convenience foods in the Netherlands shows that importantly, the factors that influence participants' initial purchase of such foods are notably different to those that affect repeat consumption, which are very similar to those affecting consumption of other, more typical foods. House's research to date shows the importance of under-acknowledged factors in establishing acceptance of insect foods and integration into people's diets: what a 'meal' consists of, how it is cooked, conventions regarding appropriate food pricing; relative household income; the availability and selection of foods and the geographical location of consumers and stores; personal or psychological factors, dietary preferences or 'foodie' approaches to eating; the taste and materiality of insects; and finally the product design. These elements are woven together in the positioning of insects as 'edible' and an article of repeat consumption, and merit further attention in research and commercial contexts.

Finally, there is an important debate in this field about who to target regarding research into consumer acceptance. Tranter (2013) advocates research looking at children and young people, who will represent the consumer base in the near future. House (2016) recommends that 'early adopters' in the current generation of consumers should be targeted, as they will provide insight into how novel insect-based foods 'fit' with established culinary practices. He also argues that instead of focusing on changing the attitudes of people who are currently averse to the idea of eating insects, researchers should investigate the factors affecting acceptance of insect-based foods among those who are already willing to eat them, as these are the people who are likely to form an early market.
Overall, the diversity of findings in contemporary consumer acceptance research suggests that different analytic emphases, as well as the employment of different disciplinary approaches and research designs, may be part of the reason that numerous, varied and sometimes contradictory factors affecting acceptance of insects as food have been identified. Crucially, the distinction between forecasted acceptance and the factors that have been found to affect actual uptake once foods are in stores, indicated here and elsewhere (House, 2016), suggests that the difficulties in attempting to project consumer acceptance may well be at least partially circumvented by an empirical focus on recent instances of food insect consumption in traditionally non-insect eating cultures. This type of research would be confined to the insect-based foods currently available in such contexts, yet would nevertheless help to more clearly elucidate the factors affecting acceptance of insects as food through an engagement with 'actual' rather than hypothesised consumption.

\section{Marketing and communication}

As shown clearly in the preceding section, the psychology of acceptance of insects as food is intrinsically linked to means of marketing and communication. Presently, the growing edible insect industry is developing various ways to promote insects as food. Strategies currently employed include both those that rely on novel technology and those that instead focus their attention on new means of communicating and framing the concept of insects as food and feed.

One form of novel technology that has been proposed to this end is $3 \mathrm{D}$ printing, which can alter both the aesthetics and texture of food. Susana Soares and Andrew Forkes from London South Bank University (London, UK), in their project 'Insects au gratin' (http://www.susanasoares. com/index.php?id=79), focus on the potential of 3D food printing of edible insects. The project represents a unique collaboration between food technology, entomology, engineering, programming and product design (Soares and Forkes, 2014). 3D food printing technology facilitates the process of modifying the initial appearance of insects - which is often seen as the main factor that deters people from eating them (Hurling and Shepherd, 2003) - and enables the development of new cooking methods and experiences. Digitising food design may increase the potential for the development of a new food aesthetic, and combines a potentially sustainable process with a potentially sustainable food product (Lilley, 2009). They have run focus of the presentation was based upon the development work for a series of successful public engagement events including 'Who's the Pest?' held at the Wellcome Collection in London, UK, and MUDAM, Luxembourg. With these events, they aimed to explore and debate the potential of entomophagy as a sustainable food source (Van Huis et $a l ., 2013)$ as well as combining with new food production 
technologies and how those could affect human perceptions of food and technology (Zellner et al., 2010). Their objective is to raise the profile of new protein sources and develop innovative food products using this new technology, and they are also investigating issues related to food aesthetics, food acceptance, novel technologies, nutrition and raw material functionality. They hope to stimulate further research into new food technologies that utilize design thinking and engineering, recognising that design can be used as a vehicle for influencing consumer behaviour and acceptance of novel foods such as insects.

Another form of novel marketing that has been piloted for use to promote insects as food, and is more immediately accessible to a wide audience, is the use of a scientific comic. A group at the Humboldt-Universität zu Berlin has developed a comic that highlights the global connections between resource use and eating habits through the concept of 'the anthropocene kitchen'. Each chapter covers a different country, introducing the foods eaten in that part of the world, and uses a range of styles to reflect global cultural diversity. The result is a low-cost tool with the potential to raise awareness about the benefits of insects as food and potentially to overcome cultural prejudices and increase consumer acceptance (Schleunitz, 2015).

Currently, there are over one hundred companies worldwide that promote and sell insects to a historically non-insecteating demographic, and employ a diverse range of strategies to market their products. Such companies face a clear set of related challenges that must be overcome: negative consumer attitudes, legislative barriers, inconsistent media coverage of insects as food, and an arms race to develop efficient farming technology that may hinder smaller startup companies. These challenges are exacerbated by a lack of knowledge in key areas, including the relationship between shellfish and insect allergens, and the viability of low-cost feed substrates and their impact on insect nutritional content. High health and safety standards, collaboration with social projects and academic research, and being proactive in developing positive public relations, will be key to the success of enterprises in this field (Stott, 2015). In parts of the world where insect consumption is traditional but decreasing, there may be other, more culturally appropriate strategies to promote insect foods. Notably, such strategies may also help to bridge the growing divide between urban and rural communities and re-establish a sense of the value of national culture. For example, FasoPro in Burkina Faso use an image of a smiling woman in traditional dress to market their caterpillar products, which are sold in urban centres (K. Hien, personal communication). Similarly the Hebo Cafe, which is based in the city of Nagoya, Japan, promotes edible wasps as one element of traditional rural cuisine (Kamimura and Nonaka, 2015). Both projects also explicitly aim to provide a new source of livelihoods for people living in rural areas. Overall, although the growing edible insect industry faces a wide range of challenges, it has several tools at its disposal, ranging from new technologies such as $3 \mathrm{D}$ printing to socially aware marketing strategies that may even help to foster positive change in the food system as a whole.

\section{Social and political aspects of insects as food}

Social and political aspects of insects as food implicitly inform all research in this emerging field, but are not always explicitly acknowledged. It is crucial to remember and recognise the manifold 'value' of edible insects to the people that traditionally harvest and consume them. Kenichi Nonaka, who spent a year living among the San bushmen of the Kalahari desert (Nonaka, 1996), found that edible insects - which he was first introduced to as a child in Japan - were culturally and linguistically significant, with specific words used to describe their taste and texture. Different collecting and processing techniques are used for edible insects found in Southern Africa (Nonaka, 1997), Laos (Nonaka et al., 1999) and Japan (Nonaka, 2010), and in all of these countries they contribute to household income. Nonaka's persona perspective on insects as food has changed dramatically in the course of his fieldwork, as he has come to understand that their value is not merely financial or for subsistence purposes, but that they belong to a diverse suite of resources enjoyed on a seasonal basis, and their use is accompanied by a rich understanding of the surrounding environment. These attributes, he argues, are the most crucial in understanding the value of insects as a source of food.

Yet the political implications of the increased promotion of insects as food are evident in the incongruences between the 'solution narrative' surrounding insects as food and their current practical integration into existing food systems, as investigated systematically by an interdisciplinary research team based in Germany, Denmark and the UK (Müller et al., 2016). While 'entomophagy' is being framed as a panacea for health, resource and climate challenges (Van Huis et al., 2013; Yates-Doerr, 2015), they found that there is more focus on technical innovation rather than considering the role of structural inequalities - which is crucial in understanding issues like malnutrition (Sen, 1981; Tomlinson, 2013; Ziegler, 2012). By drawing on empirical evidence from academia, from industry, and from the local insect trade in Southeast Asia, they critically traced the role of power between actors within the diverse realm of edible insects. In reporting first results of a systematic literature review, a systematic company and product review, and qualitative fieldwork they found that the emerging edible insects movement is generally (although not exclusively) reinforcing the existing power relations and inequalities many of its actors suggest it challenges or could challenge. Thus they recommend a repoliticisation, the inclusion of marginalized voices, and greater transparency in both 
commercial and academic sectors, as a means to foster and implement the promising potential of edible insects.

Another perspective on the political dimension of insects as food can be seen through a comparative history of food. Rebecca Roberts and Joshua Evans (Roberts and Evans, 2015) from the Nordic Food Lab (Frederiksberg, Denmark) critically compared the growing interest in insects as food with the rapid and far-reaching commercialisation of soy and its by-products. Soy, originally framed as a solution to global crises, shifted rapidly from its origins in traditional and diverse diets to international interest in it as a foodfeed-fuel complex, throughout the $20^{\text {th }}$ century. Roberts and Evans (2015) highlight the convergences - and some divergences - between the trajectory of soy and the trajectory of insects. The soy trade is now a major part of a global agri-food system that has been shaped by entrenched power relations. Rather than providing a universal solution, it is now a commodity that is fraught with problems and controversies - if we wish to ensure that the promotion of insects as food does not repeat these undesirable trends, now is the time to act.

\section{Conclusions and recommendations}

We hope that this paper has given a broad overview of some of the key themes and challenges in the field of insects as food and feed, from a predominantly European perspective. In the course of discussions at the workshop in Oxford in 2015 , and whilst writing this paper, we have also identified some gaps in current research, and several key priorities for taking the field forward.

\section{Farming, health and nutrition}

There is a wide ranging potential for using insects as food and feed, yet there remain several practical constraints that are not yet fully understood and require further investigation. Farmed insects are used mainly as feed or food, and the spent biomass and frass used as fertiliser; insect farming is currently taking place in both tropical and temperate regions and viable substrates can range from organic waste streams, to wild harvested seaweed, to commercially produced feed. We emphasize that factors such as substrate, location and use of organic wastes all have a significant influence on the overall sustainability of insect farming. We recognize that potential constraints to the use of farmed insects include currently unknown factors such as the bioavailability of key minerals found in feedstocks and their conversion efficiency into insect biomass, the possibility of pathogen transfer, and barriers to regulatory change.
We recommend:

- Research looking at the location of insect rearing facilities and the relation of this to their impact on the environment.

- Context-specific research into the environmental impacts of insect harvesting within traditional agricultural systems.

- Research into feed substrates and rearing methodologies to ensure insect breeding is efficient and sustainable.

- Research into the bioavailability of nutrients, particularly micronutrients in insect food.

- More detailed research into food safety issues (e.g. pathogens, toxins, metals and pesticides) associated with edible insects, in order to prevent hazards and inform the development of constructive legislation to regulate the use of insects as food.

- An update of legalities and regulations that were originally developed for ruminant, pig and poultry livestock, to sensibly incorporate insect farming for food and feed.

\section{The psychological, the social and the political}

The diverse conclusions of current research into marketing and psychology indicate the complexity of the issue of consumer acceptance. It is manifestly difficult to draw conclusions about 'Western' or 'European' consumer acceptance based on a range of small-scale studies that employ different methodologies in different settings. The specificities of individual insect food products, the cultural context, the population under study, and the research methods used exert a substantial influence on the diversity of research findings in this area. Furthermore, given that emerging evidence suggests a disjuncture between the type of attitudes that are reported in surveys, and the way in which insect-based food is currently being consumed in Europe, we acknowledge that attitudinal surveys may not be a viable methodology for forecasting consumer behaviour.

The edible insect industry is growing rapidly, and its promotion is frequently accompanied by promises that insects as food and feed may have the potential to address major global problems. We suggest that this 'solution narrative' obscures the social and political forces that underlie and exacerbate contemporary problems in the world food system. Insects are a promising and underutilized source of food, but the edible insect industry can only pose a real challenge to global food insecurity if we, its actors, acknowledge the social and political repercussions of current developments, and work to ensure that we are not merely reproducing problematic power disparities and unsustainable patterns of food production and consumption. 
We recommend:

- Research on consumer attitudes and behaviour that is culturally sensitive, systematic, and large-scale.

- Research that goes beyond a focus on consumer psychology, acknowledging both sociocultural factors and the influence of product attributes on consumer acceptance.

- Foster cross-sectoral collaborations in the field, in order to increase both responsibility awareness in business and the practical applicability of research.

- Research that critically investigates the social, economic and political impacts of the growing edible insect industry.

- The explicit acknowledgment of the social, economic and political impacts of developments in the edible insect industry, across all academic research in this field.

We hope that this paper, the meeting itself, and the priorities listed above, inspire further productive research. In this exciting and emerging field, a vast amount remains unknown. Edible insects certainly have a great deal of potential, but the outlook is not uniformly optimistic. Thus, we as researchers must balance our optimism with caution, contemplation and a sense of responsibility.

\section{Acknowledgements}

The authors would like to thank the Great British Sasakawa Foundation and BioBridge Ltd for financial support; the British Heart Foundation Centre on Population Approaches for Non-communicable Disease Prevention (BHFCPNP) and the Oxford Martin School for hosting and logistical support; and all presenters and delegates who contributed to the meeting, with particular thanks to Kenichi Nonaka and Pete Scarborough, whose work opened and inspired the meeting and this report. Jonas House's research received funding from the Economic and Social Research Council, grant number ES/J500215/1.

\section{References}

Black, R.E., Allen, L.H., Bhutta, Z.A., Caulfield, L.E., De Onis, M., Ezzati, M., Mathers, C., Rivera, J. and Maternal and Child Undernutrition Study Group, 2008. Maternal and child undernutrition: global and regional exposures and health consequences. Lancet 371: 243-260.

Cavallo, C. and Materia, V.C., 2015. Insects as food: a study with a choice model aimed at identifying drivers for European consumers' acceptance. Insects as Food and Feed workshop, Oxford Martin School, December 5, 2015, Oxford, UK. Available at: http://tinyurl. com/h6zxpju.

Čičková, H., Newton, G.L., Lacy, R.C. and Kozánek, M., 2015. The use of fly larvae for organic waste treatment. Waste Management 35: 68-80.

DeFoliart, G.R., 1999. Insects as food: why the western attitude is important. Annual Review of Entomology 44: 21-50.
Dossey, A.T., Morales-Ramos, J.A. and Rojas, M.G., 2016. Insects as sustainable food ingredients: production, processing and food applications. Academic Press, Cambridge, MA, USA.

Godfray, H.C.J., Beddington, J.R., Crute, I.R., Haddad, L., Lawrence, D., Muir, J.F., Pretty, J., Robinson, S., Thomas, S.M. and Toulmin, C., 2010. Food security: the challenge of feeding 9 billion people. Science 327: 812-818.

Hartmann, C., Shi, J., Giusto, A. and Siegrist, M., 2015. The psychology of eating insects: a cross-cultural comparison between Germany and China. Food Quality and Preference 44: 148-156.

House, J., 2016. Consumer acceptance of insect-based foods in the Netherlands: academic and commercial implications. Appetite 107: 47-58.

Hurling, R. and Shepherd, R., 2003. Eating with your eyes: effect of appearance on expectations of liking. Appetite 41: 167-174.

Imdad, A. and Bhutta, Z.A., 2012. Global micronutrient deficiencies in childhood and impact on growth and survival: challenges and opportunities. In: Bhutta, Z.A., Hurrell, R.F. and Rosenberg, I.H., 2012. Meeting micronutrient requirements for health and development. Karger AG, Basel, Switzerland, pp. 1-10.

Kamimura, N. and Nonaka, K., 2015. Welcome to HEBO Café: reframing traditional Japanese insect cuisine. Insects as Food and Feed workshop, Oxford Martin School, December 5, 2015, Oxford, UK. Available at: http://tinyurl.com/h6zxpju.

Kinyuru, J.N., Konyole, S.O., Onyango-Omolo, S.A., Kenji, G.M., Onyango, C.A., Owino, V.O. and Roos, N., 2015. Nutrients, functional properties, storage stability and costing of complementary foods enriched with either termites and fish or commercial micronutrients. Journal of Insects as Food and Feed 1: 149-158.

Konyole, S.O., 2014. Effect of improved complementary foods on growth and iron status of Kenyan infants. PhD thesis, University of Nairobi, Nairobi, Kenya.

Kuong, K., Chamnan, C., BungTangh, T., Skau, J.K.H., Wieringa, F., Berger, J., Friis, H., Michaelsen, K.F. and Roos, N., 2013. Development of local processed complementary food products 'WinFoods' - in Cambodia, for food aid programmes for prevention of child malnutrition. Tropical Medicine and International Health 18(S1): 194-195.

Lensvelt, E.J.S. and Steenbekkers, L.P.A., 2014. Exploring consumer acceptance of entomophagy: a survey and experiment in Australia and the Netherlands. Ecology of Food and Nutrition 53: 543-561.

Lilley, D., 2009. Design for sustainable behaviour: strategies and perceptions. Design Studies 30: 604-720.

Michie, S., Atkins, L. and West, R., 2014. The behavior change wheel: a guide to designing interventions. Silverback Publishing, London, UK.

Müller, A., Evans, J., Payne, C.L.R. and Roberts, R., 2016. Entomophagy and power. Journal of Insects as Food and Feed 2: 121-136.

Nonaka, K., 1996. Ethnoentomology of the central Kalahari San. African Study Monographs 22: 29-46.

Nonaka, K., 1997. The role of edible insects in the dietary life of the 'IGui' and 'IGGana' San in the Central Kalahari desert. Journal of African Studies 50: 81-100.

Nonaka, K., Miyagawa, S., Mizutani, R., Takenaka, C., Michiyama, H., 1999. Agriculture and village life in Laos. Japanese Society for Tropical Argiculture 43: 115-121. 
Nonaka, K., 2010. Cultural and commercial roles of edible wasps in Japan. In: Durst, P.B., Johnson, D.V., Leslie, R.N. and Shono, K. (eds.) Forest insects as food: humans bite back. FAO, Bangkok, Thailand, pp. 123-130.

Payne, C.L., Scarborough, P., Rayner, M. and Nonaka, K., 2016. A systematic review of nutrient composition data available for twelve commercially available edible insects, and comparison with reference values. Trends in Food Science and Technology 47: 69-77.

Payne, C.L.R., 2014. Wild harvesting declines as pesticides and imports rise: the collection and consumption of insects in contemporary rural Japan. Journal of Insects as Food and Feed 1: 57-65.

Ruby, M.B., Rozin, P. and Chan, C., 2015. Determinants of willingness to eat insects in the USA and India. Journal of Insects as Food and Feed 1: 215-225

Roberts, R. and Evans, J., 2015. Scaling up 'solutions': a genealogy of soy and its parallels with the incorporation of edible insects into global agri-food systems. Insects as Food and Feed workshop, Oxford Martin School, December 5, 2015, Oxford, UK. Available at: http://tinyurl.com/h6zxpju.

Salvini, S., Oseredczuk, M., Roe, M., Møller, A. and Ireland, J., 2014. Guidelines for quality index attribution to original data from scientific literature or reports for EuroFIR data interchange. EuroFIR Technical Report, WP1. 3 TG4, EuroFIR Network of Excellence, Brussels, Belgium. Available at: http://tinyurl.com/h7aomwj.

Schleunitz, M., 2015. Communicating science and raising public awareness of edible insects by a scientific comic. Insects as Food and Feed workshop, Oxford Martin School, December 5, 2015, Oxford, UK. Available at: http://tinyurl.com/h6zxpju.

Schnorr, K., 2015. Entomophagy as a solution strategy for sustainable and regional food security - a participatory approach to identify the requirements of minilivestock. Insects as Food and Feed workshop, Oxford Martin School, December 5, 2015, Oxford, UK. Available at: http://tinyurl.com/h6zxpju.

Schösler, H., De Boer, J. and Boersema, J., 2012. Can we cut out the meat of the dish? Constructing consumer-oriented pathways towards meat substitution. Appetite 58: 39-47.

Sen, A., 1981. Poverty and famines: an essay on entitlement and deprivation. Clarendon, Oxford, UK.

Soares, S. and Forkes, A., 2014. Insects au gratin - an investigation into the experiences of developing a 3D printer that uses insect protein based flour as a building medium for the production of sustainable food. In: Bohemia, E., Eger, A., Eggink, W., Kovacevic, A., Parkinson, B. and Wits, W. (eds.). Proceedings of the $16^{\text {th }}$ international Conference on Engineering and Product Design Education, Design Education and Human Technology Relations, University of Twente, the Netherlands, pp. 426-431.

Sogari, G., Menozzi, D. and Mora, C., 2015. Intention of eating edible insects: a TPB model approach. Insects as Food and Feed workshop, Oxford Martin School, December 5, 2015, Oxford, UK. Available at: http://tinyurl.com/h6zxpju.

Stott, D., 2015. The differing challenges which edible insect businesses face and how collaboration with research and social projects can make positive change. Insects as Food and Feed workshop, Oxford Martin School, December 5, 2015, Oxford, UK. Available at: http:// tinyurl.com/h6zxpju.
Swinscoe, I., Oliver, D., Gilburn, A. and Quilliam, R., 2015. Exploiting insects as feed for sustainable salmon farming - identifying the risks of pathogen transfer within the production chain. Insects as Food and Feed workshop, Oxford Martin School, December 5, 2015, Oxford, UK. Available at: http://tinyurl.com/h6zxpju.

Tan, H.S.G., Fischer, A.R.H., Tinchan, P., Stieger, M., Steenbekkers, L.P.A. and Van Trijp, H.C.M., 2015. Insects as food: exploring cultural exposure and individual experience as determinants of acceptance. Food Quality and Preference 42: 78-89.

Tan, H.S.G., Fischer, A.R.H., Van Trijp, H.C.M. and Stieger, M., 2016. Tasty but nasty? Exploring the role of sensory-liking and food appropriateness in the willingness to eat unusual novel foods like insects. Food Quality and Preference 48: 293-302.

Tomlinson, I., 2013. Doubling food production to feed the 9 billion: a critical perspective on a key discourse of food security in the UK. Journal of Rural Studies 29: 81-90.

Tranter, H., 2013. Insects creeping into English diets: introducing entomophagy to school children in a provincial town. MSc thesis, University of East Anglia, Norfolk, UK. Available at: http://tinyurl. com/hkerhgk.

Van Huis, A., 2013. Potential of insects as food and feed in assuring food security. Annual Review of Entomology 58: 563-583.

Van Huis, A., Van Itterbeeck, J., Klunder, H., Mertens, E., Halloran, A., Muir, G. and Vantomme, P., 2013. Edible insects: future prospects for food and feed security. FAO Forestry Paper 171. FAO, Rome, Italy.

Van Zanten, H.H., Mollenhorst, H., Oonincx, D.G., Bikker, P., Meerburg, B.G. and De Boer, I.J., 2015. From environmental nuisance to environmental opportunity: housefly larvae convert waste to livestock feed. Journal of Cleaner Production 102: 362-369.

Vanonhacker, F., Van Loo, E.J., Gellnyck, X. and Verbeke, W., 2013. Flemish consumer attitudes towards more sustainable food choices. Appetite 62: 7-16.

Vantomme, P., Münke, C., Van Huis, A., Van Itterbeeck, J. and Hakman, A., 2014. Insects to feed the world conference: summary report, FAO/Wageningen University, Wageningen, the Netherlands. Available at: https://www.wageningenur.nl/en/show/Insects-tofeed-the-world.htm.

Verbeke, W., 2015. Profiling consumers who are ready to adopt insects as a meat substitute in a Western society. Food Quality and Preference 39: 147-155.

Verneau, F., La Barbera, F., Kolle, S., Amato, M., Del Giudice, T. and Grunert, K.G., 2015. The effect of communication and implicit associations on consuming insects: an experiment in Denmark and Italy. Insects as Food and Feed workshop, Oxford Martin School, December 5, 2015, Oxford, UK. Available at: http://tinyurl.com/h6zxpju.

YatesDoerr, E., 2015. The world in a box? Food security, edible insects, and 'one world, one health' collaboration. Social Science and Medicine 129: 106112.

Yen, A.L., 2015. Insects as food and feed in the Asia Pacific region: current perspectives and future directions. Journal of Insects as Food and Feed 1: 33-55.

Zellner, D.A., Lankford, M., Ambrose, L. and Locher, P., 2010. Art on the plate: effect of balance and color on attractiveness of, willingness to try and liking for food. Food Quality and Preference 21: 575-578.

Ziegler, J., 2012. Wir lassen sie verhungern die Massen Vernichtung in der dritten Welt. Bertelsmann, München, Germany. 